\title{
Gender differences in awareness of diabetes mellitus among the rural population
}

\author{
lyshwarya Udaya Kumar', Jaya Prakash Murthy², Ujwal Upadhya' ${ }^{1}$, Mahesh Venkatesh ${ }^{3}$ \\ ${ }^{1}$ Assistant Professor, ${ }^{2}$ Professor, Department of Biochemistry, The Oxford Medical College and Hospital, Attibele, \\ Hobli, ${ }^{3}$ Assistant Professor, Department of Community Medicine, Sri Devaraj Urs Medical College, Kolar, Karnataka, \\ India
}

Background: Diabetes Mellitus is a chronic disorder, which is becoming rapidly epidemic in India. There are many complications occur due to uncontrolled diabetes mellitus. The outcome of diabetes depends mainly on the patient's self-management like health-related behavior, which is based on his or her knowledge. Awareness on diabetes mellitus is still a lacunae among the Indian population. Aims and Objective: To determine the knowledge regarding awareness of diabetes like the risk factors, symptoms, complications and the management among the males and females in rural population. Materials and Methods: It is a cross sectional study conducted at the tertiary care center in rural Bangalore. A structured questionnaire was used and 300 adults were assessed on their knowledge regarding the awareness of diabetes. Result: Out of 300 adults, 159 adults (53\%) had a history of diabetes. There was no gender difference observed regarding the awareness, nor the education played a role. There was significant difference observed in knowledge of diabetes Mellitus among the diabetics with respect to renal complications ( $p<0.013)$, symptoms like blurring of vision $(p<0.043)$ and burning feet $(p<0.009)$. Conclusion: Both the diabetic and non-diabetic groups had very low awareness regarding diabetes and associated risk factors. Both Males and females awareness levels were poor. Proper Diabetic education programme will help in raising public awareness of the disease.

Keywords: Diabetes Mellitus, Awareness, Health education, Knowledge, Complications
Access this article online

Website:

http://nepjol.info/index.php/AJMS

DOI: 10.3126/ajms.v8i2.16182

E-ISSN: 2091-0576

P-ISSN: 2467-9100

\section{INTRODUCTION}

It was around 1500 B.C., when Diabetes Mellitus was recognized for the first time, by the Egyptians. They defined it as a condition in which a person urinates excessively and loses weight. ${ }^{1}$ Diabetes mellitus is a chronic noncommunicable disease resulting in increased blood glucose levels, due to Insulin deficiency. ${ }^{2}$

Worldwide according to International Diabetes Federation, about 415 million people are suffering from diabetes and the number is expected to rise in the forthcoming years. In India, currently more than 62 million diabetic cases are diagnosed and it is fastly gaining the status of a potential epidemic. Maximum diabetes cases are recorded in India in the world followed by China and USA.There is a marked increase in the number of people affected with diabetes and this trend is scheduled to grow in geometric proportions in the next couple of decades. By the year 2030, number of individuals affected by diabetes in India would raise up to 79 million.,

Unfortunately, the brunt of this increase will be borne by the developing countries. These countries will see more increase in the number of diabetics, whilst the developed countries will have a relatively meager increase in numbers of around $45 \%$.

India currently faces an uncertain future in relation to the potential burden that diabetes may impose upon the country. Many influences affect the prevalence of disease throughout a country, and identification of those factors is necessary to facilitate change when facing health challenges. The overall direct healthcare costs of diabetes mellitus ranges from 2.5-15 per cent of annual health care budgets. 
This burden is likely to only increase with the projected increase in the numbers of people with diabetes. ${ }^{5}$

As per the Chennai-based Diabetes Research Centre, over about 30 per cent in urban areas go undiagnosed and 50 per cent of diabetes cases in rural India. In another study, screening has shown that the unknown to- known diabetes ratio is about 1.8:1 in urban areas, whilst it is as high as 3.3:1 in rural places. ${ }^{2}$

The crude prevalence rate of diabetes in urban areas is about $9 \%$ and that the prevalence in rural areas has also increased to around $3 \%$ of the total population. If one takes into consideration that the total population of India is more than 1000 million then one can understand the sheer numbers involved. Taking a urban-rural population distribution of 70:30 and an overall crude prevalence rate of around $4 \%$, at a conservative estimate, India is home to around 40 million diabetics and this number is thought to give India the dubious distinction of being home to the largest number of diabetics in any one country. Usually, the importance of diabetes prevention is not realized by patients until they suffer from it. ${ }^{6}$

According to the Chennai Urban Rural Epidemiology Study (CURES), nearly 25 per cent of the population was unaware of a condition called diabetes. Eleven point nine percent of the study subjects had the knowledge of the risk factors of diabetes. The World Diabetes Day is celebrated every year in order to raise the public awareness of diabetes. ${ }^{7,8}$

To improve the present condition of prevention side, much need to be done. The key issue to be addressed is to generate an awareness regarding risk factors associated with diabetes like lifestyle modification, balanced diet, control for obesity, lower stressful working condition, etc. There is very little data on the level of awareness about diabetes in developing countries like India. This is extremely important to plan the public health polices like national diabetes control programs. ${ }^{9,10}$

Knowledge about the level of awareness about diabetes in population is the first step in formulating a prevention programme for diabetes. The main objective of this study was to evaluate public knowledge, awareness and perceptions about diabetes mellitus among males and females adults in rural population of Bangalore.

\section{MATERIALS AND METHOD}

This was a cross-sectional study conducted among the people attending the tertiary care center (rural Bangalore). Patients without Diabetes and those patients with known
Diabetes and who were willing to be part of the study were included. Informed consent of the patients was taken. The study was approved by the Institutional ethical committee. All the data obtained were kept confidential. The study was carried out for duration of six months.

Pre-validated structured questionnaire regarding the cause, symptoms, complications \& Management of diabetes was administered to these patients and explained. The participants were required to answer the questionnaire using 'Yes' or 'No'. For those participants who did not know English, the questions were translated to their local Language.

Data was entered into Microsoft excel data sheet and was analyzed using SPSS 22 version software. Categorical data was represented in the form of Frequencies and proportions. Chi-square was used as test of significance. Continuous data was represented as mean and standard deviation. Independent $t$ test was used as test of significance to identify the mean difference between two groups. $p$ value $<0.05$ was considered as statistically significant.

\section{RESULTS}

A total of 300 patients took part in this study, of which $156(52 \%)$ were males and $144(48 \%)$ were females (Figure 1). Majority of the females in the study population were between 25-50 years and males were 50-75 years of age. The mean age was 49.9 years (Figure 2). A significant proportion of them were $55.4 \%$ were married. About $39 \%$ of the respondents were illiterates and $59.7 \%$ of them were literates (of which 10.3\% were graduates) (Figure 3 ).

Around $53 \%$ of the study populations were known diabetics and $18 \%$ were known Hypertensives. Majority of the study group were non-smokers (88\%). Approximately $29 \%$ of the participants knew someone who was diabetic in the family and most participants had a sibling (16.3\%),

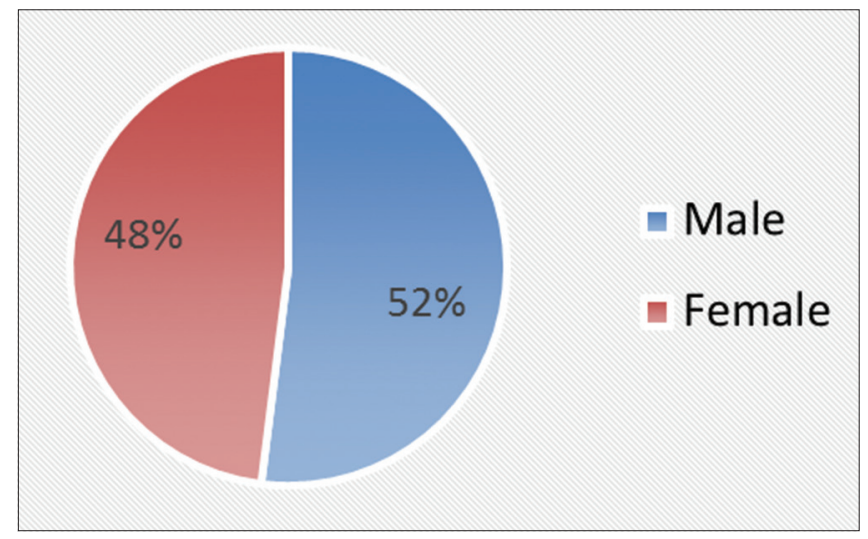

Figure 1: Sex distribution of the study group 
mother $(28.5 \%)$, father $(26.7 \%)$ or grandparents $(28.5 \%)$, in the family who were diabetic.

Subjects with past history of diabetes had higher knowledge compared to those without past history. Significant difference in knowledge was observed. Twenty nine point One percent said it could be due to insulin action inadequacy and $34.8 \%$ of the respondents said that requirement of Regular Blood sugar testing was necessary (Table 1).

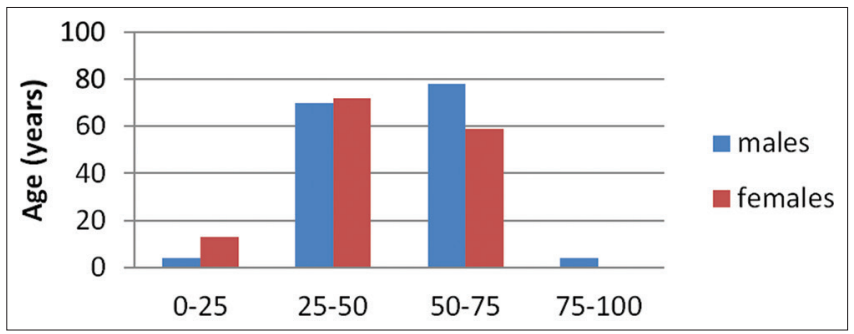

Figure 2: Age distribution of the study group

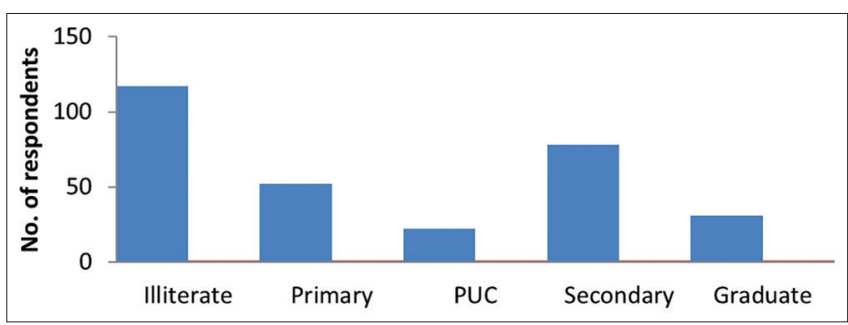

Figure 3: Education levels of the study group
Knowledge of the diabetes symptoms with respect to blurring of vision and burning feet was observed between two groups (Table 2).

Males had a better knowledge when compared to females. Subjects with past history of diabetes had higher knowledge (Figure 4).

Significant difference was observed among males for knowledge regarding risk factors between two groups. However, there was no difference among subjects with and without past history of diabetes (Figure 5).

Males had better knowledge regarding knowledge on complications with respect to diabetic foot and recurrent infections. Knowledge of the macrovascular complications of DM appeared to be somewhat better than the knowledge of microvascular complications.

Subjects with previous history of diabetes had higher knowledge regarding kidney disease complication. For example, 65\% knew that DM can result in Kidney Failure, while $56.0 \%$ of them knew that DM can be associated with Heart Disorders. Awareness of the Microvascular complications was comparatively lower among both the groups (Figure 6).

Females had significantly better knowledge in Diabetes Management aspect. Knowledge of the Management

\begin{tabular}{|c|c|c|c|c|c|}
\hline & \multicolumn{4}{|c|}{ Past H/o diabetes } & \multirow[t]{3}{*}{$\mathrm{p}$ value } \\
\hline & \multicolumn{2}{|c|}{ Yes } & \multicolumn{2}{|c|}{ No } & \\
\hline & Count & $\%$ & Count & $\%$ & \\
\hline \multicolumn{6}{|c|}{ It is a life style related disease } \\
\hline Yes & 38 & 23.9 & 27 & 19.1 & 0.319 \\
\hline No & 121 & 76.1 & 114 & 80.9 & \\
\hline \multicolumn{6}{|c|}{ It is a disease of old age } \\
\hline Yes & 49 & 30.8 & 35 & 24.8 & 0.248 \\
\hline No & 110 & 69.2 & 106 & 75.2 & \\
\hline \multicolumn{6}{|c|}{ It is contagious } \\
\hline Yes & 34 & 21.4 & 28 & 19.9 & 0.745 \\
\hline No & 125 & 78.6 & 113 & 80.1 & \\
\hline \multicolumn{6}{|c|}{ It is curable } \\
\hline Yes & 36 & 22.6 & 30 & 21.3 & 0.776 \\
\hline No & 123 & 77.4 & 111 & 78.7 & \\
\hline \multicolumn{6}{|c|}{ It is due to inadequate insulin action } \\
\hline Yes & 64 & 40.3 & 41 & 29.1 & $0.043^{*}$ \\
\hline No & 95 & 59.7 & 100 & 70.9 & \\
\hline \multicolumn{6}{|c|}{ Regular Blood sugar testing is necessary } \\
\hline Yes & 79 & 49.7 & 49 & 34.8 & $0.009^{*}$ \\
\hline No & 80 & 50.3 & 92 & 65.2 & \\
\hline \multicolumn{6}{|c|}{ Self-blood glucose monitoring is necessary } \\
\hline Yes & 36 & 22.6 & 32 & 22.7 & 0.991 \\
\hline No & 123 & 77.4 & 109 & $77.3 \%$ & \\
\hline
\end{tabular}


Table 2: Knowledge of DM by respondents

\begin{tabular}{|c|c|c|c|c|c|c|c|c|}
\hline & \multicolumn{4}{|c|}{ Yes } & \multicolumn{4}{|c|}{ No } \\
\hline & \multirow[t]{2}{*}{ Count } & \multirow[t]{2}{*}{$\%$} & \multicolumn{2}{|c|}{$95 \% \mathrm{Cl}$} & \multirow[t]{2}{*}{ Count } & \multirow[t]{2}{*}{$\%$} & \multicolumn{2}{|c|}{$95 \% \mathrm{Cl}$} \\
\hline & & & Lower \% & Upper \% & & & Lower \% & Upper \% \\
\hline \multicolumn{9}{|c|}{ Knowledge regarding symptoms } \\
\hline Excessive thirst & 151 & 50.3 & 45 & 56 & 149 & 49.7 & 44 & 55 \\
\hline Excessive urination & 188 & 62.7 & 57 & 68 & 112 & 37.3 & 32 & 43 \\
\hline Excess eating & 162 & 54.0 & 48 & 60 & 138 & 46.0 & 40 & 52 \\
\hline Blurring of vision & 122 & 40.7 & 35 & 46 & 178 & 59.3 & 54 & 65 \\
\hline Burning feet & 113 & 37.7 & 32 & 43 & 187 & 62.3 & 57 & 68 \\
\hline Delayed wound healing & 102 & 34.0 & 29 & 39 & 198 & 66.0 & 61 & 71 \\
\hline Tiredness & 149 & 49.7 & 44 & 55 & 151 & 50.3 & 45 & 56 \\
\hline \multicolumn{9}{|c|}{ Knowledge regarding risk factors } \\
\hline Excessive intake of sugar & 112 & 37.3 & 32 & 43 & 188 & 62.7 & 57 & 68 \\
\hline Stress & 100 & 33.3 & 28 & 39 & 200 & 66.7 & 61 & 72 \\
\hline Lack of physical activities & 95 & 31.7 & 26 & 37 & 205 & 68.3 & 63 & 74 \\
\hline Family history & 97 & 32.3 & 27 & 38 & 203 & 67.7 & 62 & 73 \\
\hline \multicolumn{9}{|c|}{ Knowledge regarding complications } \\
\hline Kidney disease & 171 & 57.0 & 51 & 63 & 129 & 43.0 & 37 & 49 \\
\hline Heart disease & 155 & 51.7 & 46 & 57 & 145 & 48.3 & 43 & 54 \\
\hline Eye disease & 181 & 60.3 & 55 & 66 & 119 & 39.7 & 34 & 45 \\
\hline Delayed wound healing & 119 & 39.7 & 34 & 45 & 181 & 60.3 & 55 & 66 \\
\hline Recurrent infections & 116 & 38.7 & 33 & 44 & 184 & 61.3 & 56 & 67 \\
\hline Effect on nerves & 139 & 46.3 & 41 & 52 & 161 & 53.7 & 48 & 59 \\
\hline \multicolumn{9}{|c|}{ Knowledge regarding Management } \\
\hline Diet only & 181 & 60.3 & 55 & 66 & 119 & 39.7 & 34 & 45 \\
\hline Medicines only & 230 & 76.7 & 72 & 81 & 70 & 23.3 & 19 & 28 \\
\hline Exercise only & 186 & 62.0 & 56 & 68 & 114 & 38.0 & 32 & 44 \\
\hline Diet+Medicines+Exercise & 178 & 59.3 & 54 & 65 & 122 & 40.7 & 35 & 46 \\
\hline
\end{tabular}

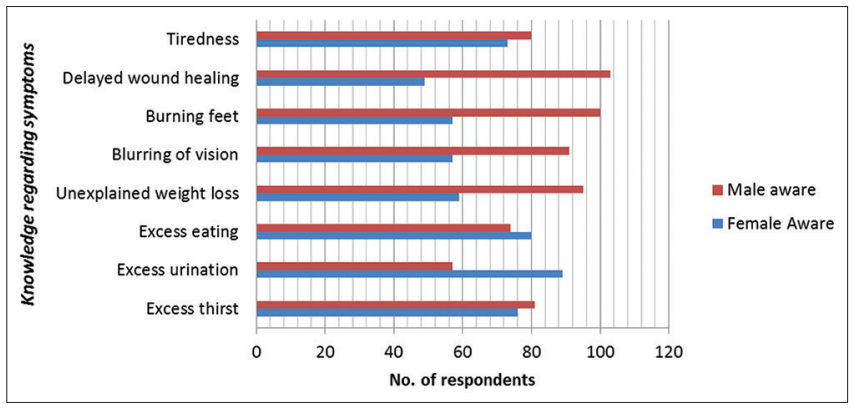

Figure 4: Knowledge regarding symptoms of DM

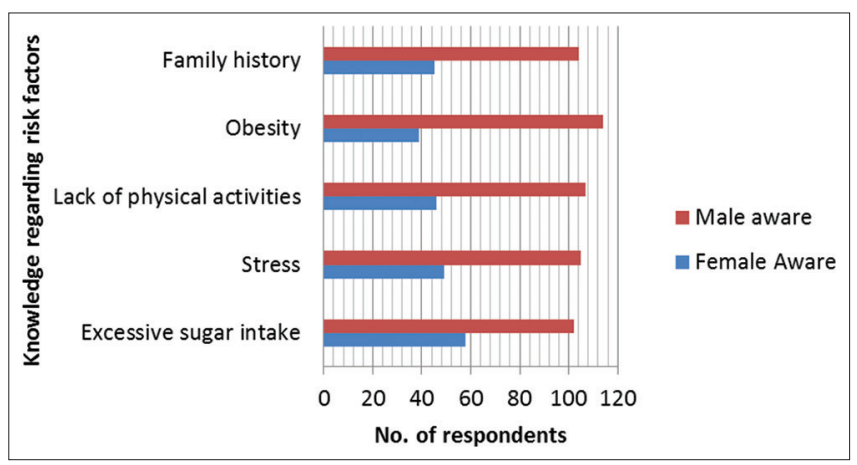

Figure 5: Comparison of knowledge regarding risk factors of diabetes mellitus

measures was poor among both the groups, those with and without past history of Diabetes. Significant proportion of the participants said that diabetes can be managed by medicines alone $-73 \%$, by dietary modifications alone $-59 \%$ and by physical activity alone $-62 \%$. However, $58 \%$ of them believe that combination of healthy Diet, Medicines and along with the physical activity will help in better Management of DM (Figure 7).

\section{DISCUSSION}

Proper management of Diabetes is a complex and challenging task especially in developing countries like India. The major lacunae is the lack of knowledge about diabetes. Better the knowledge of diabetes, better is the Glycemic control. ${ }^{11,12}$

Majority of our respondents were unaware of the risk factors or the complications of diabetes. This reflects a significant lack of knowledge about diabetes, which may have an adverse outcome in terms of prevention, which again affects the economy of the country.

The results showed that there is a statistically significant difference in the mean knowledge of the participants with different age ranges, but there was no significant difference in the knowledge among different gender. 


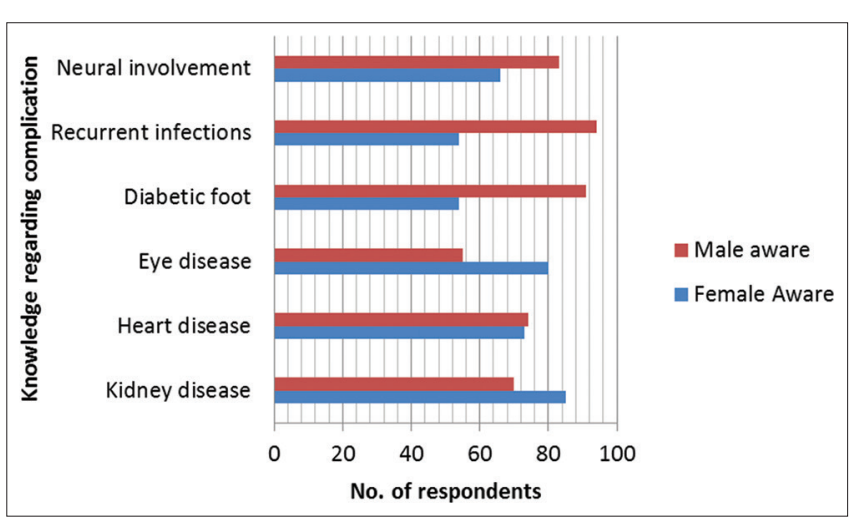

Figure 6: Knowledge regarding Complications of DM

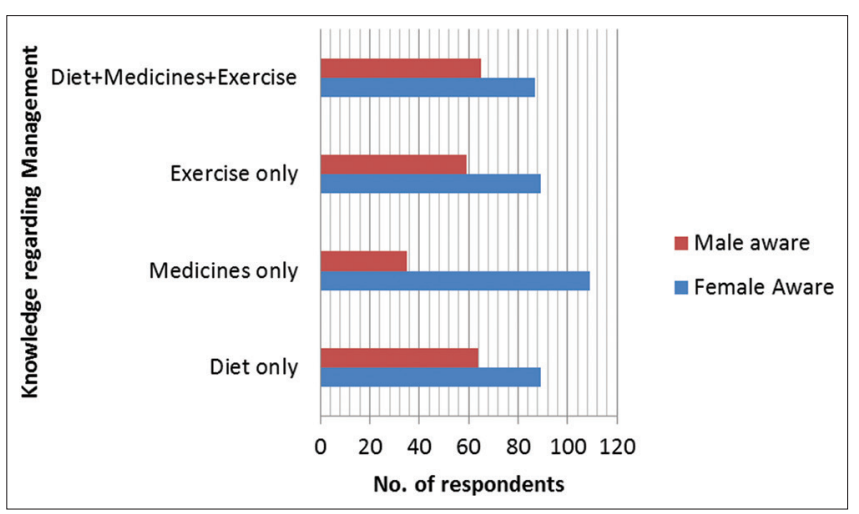

Figure 7: Knowledge regarding Management of DM

In this study, the majority of the respondents were illiterates $(39 \%)$. Hardly, $10 \%$ of the respondents were graduates. This results are in contrast to other studies like Chennai based study and European study, where age and educational status plays an important role in the Diabetes knowledge of the population. Higher the education level better is the knowledge. ${ }^{1314}$

Many studies have revealed that women had better knowledge about diabetes when compared to men. ${ }^{15-17}$

According to Pond et al., ${ }^{18}$ women had worse diabetes control than men, probably because they often have to balance both their diabetes care and the family care. A German study showed significant gender-specific differences in the association of adherence and poor glycaemic control. In men, poor glycaemic control was found in $37 \%$ of the participants and $19 \%$ of women participants reporting non-adherence. ${ }^{19}$

Our study shows no gender difference regarding the diabetes knowledge. However, women had better knowledge with respect to the cause of diabetes. Similarly, there was no gender difference observed even in the Ethiopian study conducted. ${ }^{20}$

According to Hibbard, the attitude and behavior of men and women towards diabetes care is different. ${ }^{21}$ Women are more sensitive to illnesses and seek medical advice. Handerson study found that women have a greater interest and concern for diabetes ${ }^{22}$ Women make greater use of diabetes services and have a larger network of people with whom to discuss medical problems. ${ }^{23}$

Women have greater responsibility in terms of her family health. Differences between men and women with regard to their attitudes and behaviors associated with diabetes have not received as much attention in the literature. ${ }^{24}$

There was no significant difference in the knowledge of diabetes among the diabetics and non-diabetics. Diabetic patients had a better knowledge regarding the renal complications $(\mathrm{p}<0.013)$, and the symptoms like blurring of vision $(p<0.043)$ and burning feet $(p<0.009)$. Nonetheless, the patients without diabetes were also able to identify the risk factors of diabetes, but not well versed with the complications of diabetes. Our study is in accordance with the study conducted by Tham et al..$^{25}$

Tham et al showed that the knowledge of patients with and without diabetes was not statistically significant. But according to Ding et al, diabetics (81\%) had better knowledge compared to non-diabetics $(64 \%){ }^{26}$

\section{CONCLUSION}

It is very much important to emphasize the fact that diabetes mellitus is a non-curable condition which can be managed well. Hence, it becomes necessary to stress on the cause of diabetes, risk factors, symptoms, complications and the management of diabetes mellitus. The need of the hour is "Diabetes health education" for both diabetics as well as healthy adults. In developing country like India, Diabetes education will definitely play a crucial role in creating public awareness about diabetes.

\section{Limitations of the study}

The studies on gender differences regarding diabetes mellitus have been cross sectional most of the time. There is a need for more longitudinal studies about gender and diabetes.

\section{REFERENCES}

1. Polonsky K. The Past 200 years in Diabetes. N Engl J Med 2012; 367(14):1332-1340.

2. Kumar A, Goel MK, Jain RB, Khanna P and Chaudhary V. India towards diabetes control: Key issues. AMJ 2013; 6(10):524-531.

3. International Diabetes Federation. IDF Diabetes Atlas, $7^{\text {th }}$ ed. Brussels, Belgium: International Diabetes Federation, 2015.

4. World Health Organization (WHO). Country and regional data on 
diabetes. Geneva: WHO; 2016.

5. Diabetes India - Indian Task Force [Internet]. Diabetesindia.com. 2016 [cited 30 December 2016]. Available from: http://www. diabetesindia.com/diabetes/itfdci.htm.

6. Sahani NC, Moharana PR, Sahu A, Satapathy DM and Tripathy RM. Nutritional Status and its effect on prevalence of Diabetes Mellitus among Rural population. The Indian Journal of nutrition and Dietetics 2013; 50(2):56-62.

7. Mohan D, Raj D, Shanthirani CS, Datta M, Unwin NC, Kapur A, et al. Awareness and knowledge of diabetes in Chennai-the Chennai Urban Rural Epidemiology Study (CURES-9). J Assoc Physicians India 2005; 53:283-287.

8. [Internet]. 2016 [cited 30 December 2016]. Available from: http://www.hindustantimes.com/India-worlddiabetes-capital/ Article1-245889.aspx.

9. Viswanathan $\mathrm{V}$ and Ranjan S. Diabetes - An ancient disease, epidemic \& an economic burden for the present era. Indian J Med Res 2016; 143:389-391.

10. Wu $Y$, Ding $Y$, Tanaka $Y$ and Zhang W. Risk factors contributing to type 2 diabetes and recent advances in the treatment and prevention. International journal of medical sciences 2014; 11(11): 1185-1200.

11. Fenwick E, Xie J, Rees G, Finger R and Lamoureux E. Factors Associated with Knowledge of Diabetes in Patients with Type 2 Diabetes Using the Diabetes Knowledge Test Validated with Rasch Analysis. PLoS ONE. 2013; 8(12):e80593.

12. Hassali M, Saleem F, Chua G, Haq N and Aljadhey H. A Cross Sectional Assessment of Knowledge towards Diabetes Mellitus among Urban Poor Population of Penang, Malaysia. Value in Health 2013; 16(3):A1-A298.

13. Rani PK, Raman R, Subramani S, Perumal G, Kumaramanickavel $\mathrm{G}$ and Sharma T. Knowledge of diabetes and diabetic retinopathy among rural populations in India and the influence of knowledge of diabetic retinopathy on attitude and practice. Rural and Remote Health 8(3):838. [serial online] 2008. [cited30 December 2016].

14. Sacerdote C, Ricceri F, Rolandsson O, Baldi I, Chirlaque MD, Feskens $\mathrm{E}$, et al. Lower educational level is a predictor of incident type 2 diabetes in European countries: The EPIC-InterAct study.
Int J Epidemiol 2012; 41(4):1162-1173.

15. Borges TT, Rombaldi AJ, Knuth AG and Hallal PC. Knowledge on risk factors for chronic diseases: A population-based study. Cad Saude Publica 2009;25(7):1511-1520.

16. Majumder N, Majumder $\mathrm{N}$ and Datta SS. Knowledge and perception of mothers of under five children regarding etiology of type-II diabetes mellitus in Agartala, Tripura. Health Agenda 2013;1(3):64-70.

17. Shah VN, Kamdar PK and Shah N. Assessing the knowledge, attitudes and practice of type 2 diabetes among patients of Saurashtra region, Gujarat. Int J Diabetes Dev Ctries 2009; 29(3):118-122.

18. Pond $\mathrm{N}$, Sturock $\mathrm{N}$ and Jeffcoate $\mathrm{W}$. Age related changes in glycosylated haemoglobin in patients with IDDM. Diabetic Medicine 1996; 13:510-513.

19. Raum E, Kramer HU, Ruter G, Rothenbacher D, Rosemann T, Szecsenyi J, et al. Medication non-adherence and poor glycaemic control in patients with type 2 diabetes mellitus. Diabetes Res ClinPract 2012; 97(3):377-384.

20. Bahru $Y$ and Abdukkadir J. Assessment of diabetes education in the teaching hospital, Addis Ababa, Ethiopia. Diabet Med 1993;10(9):870-873.

21. Hibbard JH and Pope CR. Gender roles illness orientation and use of medical services. Soc Sci Med 1983;17:129-137.

22. Anderson RM, Fitzgerald JT and Oh MS. The relationship between diabetes- related attitudes and patient's self-reported adherence. Diabetes Educ 1993; 19(4):287-292.

23. Green KE. Common illness and self-care. J Community Health 1990; 15:329-338.

24. Sharpe PA, Clark NM and Janz NK. Differences in the impact and management of heart disease between older women and men. Women \& Health 1991; 17:25-43.

25. Tham KY, Ong JJ, Tan DK and How KY. How much do diabetic patients know about diabetes mellitus and its complications? Ann Acad Med Singapore 2004; 33:503-509.

26. Ding $\mathrm{CH}$, Teng $\mathrm{CL}$ and Koh $\mathrm{CN}$. Knowledge of diabetes mellitus among diabetic and non diabetic patients in Kilinik Kesihatan Seremban. Med J Malaysia 2006; 61(4):399-404.

\section{Authors Contribution:}

Authors Contribution:
IUK - Principal Investigator, Concept and design of the study, reviewed the literature, collected the data, manuscript preparation and critical revision of the manuscript; JPM - helped in preparing first draft of manuscript; $U$ - prepared first draft of manuscript and critical revision of the manuscript; MV - statistically analyzed and interpreted; S - Review of study.

Source of Support: Nil, Conflict of Interest: None declared. 